\title{
Evaluation of the Effectiveness of Preloaded IOL Injectors in Surgical Time
}

\author{
Wilson Takashi Hida',2, Leonardo da Cunha Silva Braga',2, Danilo Varela Kniggendorf2, \\ Celso Takashi Nakano², Antonio Francisco Pimenta Motta², Andre Lins de Medeiros'², \\ Walton Nosé2,3
}

\author{
${ }^{1}$ Hospital Oftalmológico de Brasília, Brasília, Brasil \\ ${ }^{2}$ Centro de Estudos Oftalmológicos Renato Ambrósio, Brasília, Brasil \\ ${ }^{3}$ UNIFESP, São Paulo, Brasil \\ Email: *andre_linz@msn.com
}

How to cite this paper: Hida, W.T., da Cunha Silva Braga, L., Kniggendorf, D.V., Nakano, C.T., Motta, A.F.P., de Medeiros, A.L. and Nosé, W. (2021) Evaluation of the Effectiveness of Preloaded IOL Injectors in Surgical Time. Open Journal of Ophthalmology, 11, 339-347.

https://doi.org/10.4236/ojoph.2021.114028

Received: July 22, 2021

Accepted: November 27, 2021

Published: November 30, 2021

Copyright $\odot 2021$ by author(s) and Scientific Research Publishing Inc. This work is licensed under the Creative Commons Attribution International License (CC BY 4.0).

http://creativecommons.org/licenses/by/4.0/

\begin{abstract}
Background: The implantation of the intraocular lens (IOL) is still subject to error and complication, as it can result in traumatic opening of the IOL leading to rupture of the posterior capsule and zonular dialysis, it takes time to train paramedic teams to assemble such IOLs with the manual injectors. Moreover, there is a potential risk of comtamination and endophthalmitis as there is manipulation of the IOL and cartridge. The preloaded IOLs tend to reduce those unwanted results and may optimize the surgical time. Purpose: The aim of this study is to compare the effectiveness and implantation time between three injectors and three intraocular lenses, two pre-loaded and one conventional. Methodology: Videos of thirty patients undergoing cataract surgery from December 2019 to December 2020 at the Hospital Oftalmológico de Brasília (HOB), Brasília, Brazil were included in this observational, analytical retrospective study, non randomized. All patients had their surgeries recorded, from which the time of injection and opening of the intraocular lens (IOL) was extracted, 20 eyes were implanted with preloaded intraocular lens, and 10 eyes with conventional IOL implant. The patients were divided into three groups with similar eye characteristics. The first received the $\mathrm{Au}-$ tonoMe ${ }^{\text {tw }}(\mathrm{CE})$ injector with the Clareon ${ }^{\circledR}$ IOL, the second the Isert ${ }^{\mathrm{tm}}$ injector (I) with the Hoya ${ }^{\circledR}$ IOL, and the third was injected with Johnson \& Johnson Platinum 1 Series injector used to deliver Sensar ${ }^{\circledR}$ One AAB00 lens. The Welch test and Tukey's Post Hoc test were used in the statistical analysis. Results: It was observed that there was a statistical significance regarding the presence of a haptic stuck (5 Clareon vs 0 Sensar and Hoya), between the mean opening time of the IOL optics Sensar One, Hoya and Clareon (25.00 vs 31.40 vs 11.70 $\mathrm{s}, \mathrm{p}<0.001$ ) and between the total time (the injection time more the opening
\end{abstract}


time of the IOL) in relation to Hoya and Clareon lenses (39.50 s vs $19.60 \mathrm{~s}, \mathrm{p}$ $<0.001$ ); the total time of the Sensar IOL was $31.30 \mathrm{~s}$. The opening time of the IOL optics was significantly longer for the Sensar One and Hoya groups compared to Clareon group, and the total time of Hoya group was significantly longer compared to the total time of the Clareon group. Conclusion: The study demonstrated that the choice of injector and IOL set can significantly affect the total time of IOL implantation. However, there was no difference regarding complications and collateral damage depending on the set chosen for the implant.

\section{Keywords}

Cataract, Intraocular Lens, Preloaded Injectors, IOL Implant Efficacy

\section{Introduction}

Modern cataract surgery has evolved considerably in recent years thanks to technological advances in the field of robotic engineering, computing and scientific research on fluidics, surgical equipment and materials for making intraocular lenses (IOLs) [1] [2]. Such changes provided the surgeon with the handling of smaller, more precise and more dexterous surgical instruments. In the hands of an experienced surgeon, bringing together the most modern, in terms of phacoemulsification apparatus and femtosecond laser to perform the main steps of cataract surgery, it can be performed between three to five minutes with minimal inflammatory reaction, excellent postoperative recovery and quick resumption of the patient's daily activities. This has provided cataract surgery as the cleanest surgery performed in the modern world for therapeutic purposes [3]. Thus, the number of patients exchanging a clear lens for an intraocular lens more precociously has been increasing in recent years with a goal to improving visual quality and quality of life, which has become a standard of exigence by patients. Furthermore, the longevity of the world population is increasing and the number of people with cataracts is increasing.

In order to meet the degree of demand of patients and the increased demand in the number of surgeries, a very important step, which we will discuss here, is the implantation of the IOL. It is one of the last steps of the surgery, but it can still be subject to error and complication. The main drawback in this step is related to the delay and incorrect assembly of the IOL using a manual injector, something apparently innocent, but which can result in traumatic opening of the IOL and rupture of the posterior capsule [4] [5]. Furthermore, it takes time to train specialized teams to assemble such lenses and still have to select the correct injector for each lens. Another rare but potentially serious factor is the risk of contamination of the surgical instrument and possible endophthalmitis as a consequence. The preloaded lenses have came to reduce all these unwanted results and optimize the surgical time, making it possible to increase the number of 
surgeries performed per shift by the same surgeon [6] [7]. The aim of this study is to compare the effectiveness and delivery time of the IOL between two injectors with preloaded lenses and a conventional control group. 10 videos with Clareon, 10 with Hoya and 10 with Sensar One IOLs were chosen. To our knowledge, this is the first study to compare injection time and opening time between intraocular lenses and between different delivery systems.

\section{Methodology}

This is an observational, analytical retrospective study non-randomized. The screening and selection of patients took place in the Cataract Surgery sector of the Brasília ophthalmological hospital (HOB), through the analysis of medical record videos of thirty patients undergoing cataract surgery from December 2019 to December 2020 at HOB. The sample size of 30 patients was defined to make statistical comparisons between groups and the interval of confidence was defined as $95 \%$.

After patient selection according to the inclusion and exclusion criteria of the study, the record of their surgeries was downloaded from the surgical premises and watched with the purpose to use in the study. The first ten watched videos regarding the implantation of clareon, Hoya and Sensar One lenses were chosen (Table 1).

The main objective was to compare the results obtained between performing the intraocular lens delivery using preloaded injectors, and a conventional injector, considering whether it is difficult to inject or open the IOL, to evaluate which injector and IOL would be the feasible for delivery of the intraocular lens inside the capsular bag without causing damage.

The results were divided into descriptive and association analysis. Data analysis was performed using the IBM SPSS program (Statistical Package for the Social Sciences) 23, 2015. The level of significance used in the entire study was $5 \%$.

The acquired data were used to make tables and graphs that exhibit the total injection and opening time of each IOL group in seconds. The average time of

Table 1. Inclusion and exclusion criteria.

\begin{tabular}{ll}
\hline Inclusion criteria & Exclusion criteria \\
\hline Age over 50 years & Any previous eye surgeries \\
Use of Clareon, Hoya or Sensar One & Eye trauma \\
Surgery recorded at the HOB & $\begin{array}{l}\text { Anterior chamber depth below } 2.8 \mathrm{~mm} \text { or above } \\
3.6 \mathrm{~mm}\end{array}$ \\
IOL diopters between 20.00 and 24.00 & \\
IOL preheated to a minimum temperature of $20^{\circ} \mathrm{C}$ and a maximum temperature of $40^{\circ} \mathrm{C}$ \\
Good pupillary dilation in the perioperative period making it possible to visualize the \\
IOL border \\
Clear cornea during the perioperative period
\end{tabular}


injection and opening of the IOL was calculated for each injector group and finally compared the injectors with their respective IOLs in terms of difficulty in injecting and opening the IOL, surgical time and risks inherent to the procedure.

The results of the tables were compared for each injector group and IOL in graphs evaluating the injection times and total opening time of the IOL. This study evaluated 30 patients, with a total of 30 eyes, in patients over 50 years of age who underwent cataract extraction with IOL implantation using preloaded and conventional injectors. 10 Isert $^{\mathrm{tm}}$ (I) injectors were used to deliver the Hoya IOL, 10 AutonoMe ${ }^{\mathrm{Tm}}$ (CE) injectors loaded with the clareon ${ }^{\circledR}$ IOL, and 10 Sensar One IOLs coupled to the Johnson \& Johnson Platinum 1 Series injector. The same surgeon (WTH) performed the cataract extraction and IOL implantation using the same technique. First an incision clear corneal of $2.4 \mathrm{~mm}$ executed in the most curved meridian of the cornea with a stainless steel keratome. Then a continuous curvilinear capsulorhexis of approximately $5 \mathrm{~mm}$ in diameter made with Ultrata forceps. Afterwards, complete hydrodissection and endocapsular phacoemulsification of the nucleus with aspiration of the residual cortex. The lens capsule was inflated with a standard ophthalmic viscosurgical device (OVD) (vistagel) for all, and one of the three IOLs (Hoya ${ }^{\circledR}$, Clareon $^{\circledR}$, Sensar One ${ }^{\circledR}$ ) were placed in the capsular bag using their respective injectors Isert $^{\mathrm{Tm}}$, AutonoMe ${ }^{\mathrm{Tm}}$, Johnson \& Johnson Platinum 1 Series). After insertion of the IOL, the OVD was completely evacuated and the anterior chamber was sealed at the incision sites through hydration of the autosealing cornea. The Hoya lens has a total diameter of $12.5 \mathrm{~mm}$ and an optical diameter of $6 \mathrm{~mm}$, hydrophobic acrylic material, fully preloaded injector. The Clareon lens has hydrophobic acrylic material, surface with a total diameter of $13.00 \mathrm{~mm}$ and a fully preloaded injector. The Sensar 1 lens has hydrophobic acrylic material, with a total diameter of $13.00 \mathrm{~mm}$ and an optical diameter of $6 \mathrm{~mm}$.

\section{Results}

A total of 30 eyes from 30 patients ( 15 men and 15 women), aged over 50 years were included in the study. The qualitative clinical variables were presented by means of frequency (n) and percentage (\%) in Table 2. The operated eye was the left $(\mathrm{n}=14)$ in $46.7 \%$, and the right $(\mathrm{n}=16)$ in $53.3 \%$ of the occasions. The number of lenses implanted was the same for each group, Sensar One, Hoya, Clareon $(10,10,10)$. It was noticed a haptic stuck to 5 lenses $(16.7 \%)$. Table 3 shows the descriptive measures used for the quantitative variables: mean, median, standard deviation, minimum, maximum and interquartile range, the IOL diopter ranged between 20.00 to 24.00 diopters, the anterior chamber measurement tanged between 2.80 to $3.65 \mathrm{~mm}$, the IOL injection time ranged between 3.00 to 14.00 secinds, the opening time of the IOL optics ranged between 10.00 to 63.00 seconds and the total time, which consisted of the IOL injection time plus the opening time of the IOL opticd ranged between 18.00 to 77.00 seconds.

The type of lens implanted was associated with qualitative variables, using 
Table 2. Descriptive analysis of the qualitative variables of patients over 50 years old that was cataract extraction with IOL implantation in two preloaded and one conventional injectors realized in sector of Cataract Surgery at the Hospital Oftalmológico de Brasília. December 2019 to December 2020.

\begin{tabular}{|c|c|c|c|}
\hline & & $\mathrm{n}$ & $\%$ \\
\hline \multirow{2}{*}{ Opereted eye } & Left & 14 & 46.7 \\
\hline & Right & 16 & 53.3 \\
\hline \multirow{3}{*}{ Implanted lens } & Sensar One & 10 & 33.3 \\
\hline & Hoya & 10 & 33.3 \\
\hline & Clareon & 10 & 33.3 \\
\hline \multirow{2}{*}{ Haptic stuck } & Yes & 5 & 16.7 \\
\hline & No & 25 & 83.3 \\
\hline \multirow{2}{*}{ Genre } & Male & 15 & 50.0 \\
\hline & Female & 15 & 50.0 \\
\hline Total & & 30 & 100.0 \\
\hline
\end{tabular}

Table 3. Descriptive analysis of the quantitative variables of patients over 50 years old that had cataract extraction with IOL implantation with two preloaded and one conventional injectors.

\begin{tabular}{cccccccc}
\hline & $\mathbf{n}$ Average Median & $\begin{array}{c}\text { Standard } \\
\text { deviation }\end{array}$ & Minimum Maximum & $\begin{array}{c}\text { Interquartile } \\
\text { range }\end{array}$ \\
\hline $\begin{array}{c}\text { Implanted lens } \\
\text { diopter }\end{array}$ & 30 & 21.32 & 21.50 & 1.14 & 20.00 & 24.00 & 2.00 \\
$\begin{array}{c}\text { Anterior chamber } \\
\text { measurement }\end{array}$ & 30 & 3.21 & 3.26 & 0.24 & 2.80 & 3.65 & 0.32 \\
$\begin{array}{c}\text { IOL injection time } \\
\begin{array}{c}\text { Opening time of } \\
\text { IOL optics }\end{array}\end{array}$ & 30 & 6.90 & 6.50 & 2.20 & 3.00 & 14.00 & 3.00 \\
$\begin{array}{c}\text { Total time } \\
\text { Ton }\end{array}$ & 25 & 32.24 & 30.00 & 13.75 & 18.00 & 77.00 & 17.50 \\
\hline
\end{tabular}

Pearson's chi-square test with Monte Carlo simulation when necessary (at least one cell had an expected frequency less than 5).

It can be seen in Table 4 that only the stuck strap variable was statistically associated with the implanted lens. Patients who used the Clareon lens had significantly more haptic stuck compared to patients who used the Sensar One and Hoya groups. $50 \%$ of patients implanted with the Clareon lenses had haptic stuck.

The implanted lens variable was also associated with the quantitative variables, through the unidirectional Analysis of Variance, that is, it took into account the differences in the mean variation between and within the evaluated populations (for each type of lens). However, the analysis of variance assumes normal 
Table 4. Analysis of the association between the type of lens implanted and the qualitative variables of patients over 50 years old that was cataract extraction with IOL implantation in two preloaded and one conventional injectors realized in sector of Cataract Surgery at the Hospital Oftalmológico de Brasília. December 2019 to December 2020.

\begin{tabular}{|c|c|c|c|c|c|c|c|}
\hline & & & \multicolumn{3}{|c|}{ Implanted lens } & \multirow{2}{*}{ Total } & \multirow{2}{*}{$P^{*}$} \\
\hline & & & Sensar One & Hoya & Clareon & & \\
\hline \multirow{4}{*}{ Operated eye } & \multirow{2}{*}{ Left } & $\mathrm{n}$ & 5 & 6 & 3 & 14 & \multirow{4}{*}{0.537} \\
\hline & & $\%$ & 50.00 & 60.00 & 30.00 & 46.67 & \\
\hline & \multirow{2}{*}{ Right } & $\mathrm{n}$ & 5 & 4 & 7 & 16 & \\
\hline & & $\%$ & 50.00 & 40.00 & 70.00 & 53.33 & \\
\hline \multirow{4}{*}{ Haptic stuck } & \multirow{2}{*}{ Yes } & $\mathrm{n}$ & 0 & 0 & 5 & 5 & \multirow{4}{*}{0.006} \\
\hline & & $\%$ & 0.00 & 0.00 & 50.00 & 16.67 & \\
\hline & \multirow{2}{*}{ No } & $\mathrm{n}$ & 10 & 10 & 5 & 25 & \\
\hline & & $\%$ & 100.00 & 100.00 & 50.00 & 83.33 & \\
\hline \multirow{4}{*}{ Genre } & \multirow{2}{*}{ Male } & $\mathrm{n}$ & 7 & 5 & 3 & 15 & \multirow{4}{*}{0.261} \\
\hline & & $\%$ & 70.00 & 50.00 & 30.00 & 50.00 & \\
\hline & \multirow{2}{*}{ Female } & $\mathrm{n}$ & 3 & 5 & 7 & 15 & \\
\hline & & $\%$ & 30.00 & 50.00 & 70.00 & 50.00 & \\
\hline \multirow{2}{*}{ Total } & & $\mathrm{n}$ & 10 & 10 & 10 & 30 & \\
\hline & & $\%$ & 100,00 & 100.00 & 100.00 & 100.00 & \\
\hline
\end{tabular}

*Pearson's Chi-square test with Monte Carlo simulation when necessary.

distribution of errors and homoscedasticity, that is, homogeneity of variances. For the variables Diopter of the implanted lens, opening time of the IOL optics and Total time, there was rejection of the homogeneity of the variances, measured by the Levene test, therefore, the Welch test was used, which makes a correction for situations in which there is heteroscedasticity (different variances between groups). No null hypothesis of normality for the errors of the Analysis of variance using the Lilliefors test was rejected. Tukey's Post Hoc test was used for variables that showed a significant difference in means.

Table 5 shows that there was statistical significance between the opening time of the IOL optics and the total time in relation to the type of lens, with the clarion lens opening faster than the other intraocular lenses. In Table 6 (multiple comparison-Post $\mathrm{Hoc}$ ) it is possible to evaluate that the difference for the opening time of the IOL optics between the Sensar One and Clareon lenses and between Hoya and Clareon, with the averages of the opening time of the IOL optics being significantly higher for Sensar One and Hoya lenses compared to the Clareon lens.

For the total time, the statistiscal significance was between the Hoya lens and Clareon, with the total time on the Hoya lenses being significantly longer compared to the time for the Clareon lens. However, the 5 lenses with a stuck strap 
Table 5. Analysis of variance for the quantitative variables in relation to the type of lens implanted.

\begin{tabular}{|c|c|c|c|c|c|c|c|c|c|c|}
\hline & & \multirow[t]{2}{*}{$\mathbf{n}$} & \multirow[t]{2}{*}{ Average } & \multirow{2}{*}{$\begin{array}{l}\text { Standard } \\
\text { deviation }\end{array}$} & \multirow{2}{*}{$\begin{array}{l}\text { Standard } \\
\text { Error }\end{array}$} & \multicolumn{2}{|c|}{$\begin{array}{l}\text { 95\% confidence interval } \\
\text { for medium }\end{array}$} & \multirow{2}{*}{ Minimum } & \multirow[t]{2}{*}{ Maximum } & \multirow[t]{2}{*}{$P^{*}$} \\
\hline & & & & & & Inferior limit & Upper limit & & & \\
\hline \multirow{4}{*}{$\begin{array}{l}\text { Implanted lens } \\
\text { diopter }\end{array}$} & Sensar One & 10 & 21.70 & 1.53 & 0.48 & 20.60 & 22.80 & 20.00 & 24.00 & \multirow{4}{*}{0.449} \\
\hline & Hoya & 10 & 21.30 & 0.67 & 0.21 & 20.82 & 21.78 & 20.00 & 22.00 & \\
\hline & Clareon & 10 & 20.95 & 1.04 & 0.33 & 20.21 & 21.69 & 20.00 & 23.00 & \\
\hline & Total & 30 & 21.32 & 1.14 & 0.21 & 20.89 & 21.74 & 20.00 & 24.00 & \\
\hline \multirow{4}{*}{$\begin{array}{c}\text { Previous } \\
\text { chamber } \\
\text { measurement }\end{array}$} & Sensar One & 10 & 3.30 & 0.24 & 0.08 & 3.13 & 3.48 & 2.94 & 3.65 & \multirow{4}{*}{0.340} \\
\hline & Hoya & 10 & 3.16 & 0.23 & 0.07 & 2.99 & 3.33 & 2.80 & 3.57 & \\
\hline & Clareon & 10 & 3.16 & 0.23 & 0.07 & 3.00 & 3.32 & 2.82 & 3.40 & \\
\hline & Total & 30 & 3.21 & 0.24 & 0.04 & 3.12 & 3.30 & 2.80 & 3.65 & \\
\hline \multirow{4}{*}{ IOL injection time } & Sensar One & 10 & 6.30 & 1.49 & 0.47 & 5.23 & 7.37 & 3.00 & 8.00 & \multirow{4}{*}{0.200} \\
\hline & Hoya & 10 & 8.10 & 2.73 & 0.86 & 6.15 & 10.05 & 5.00 & 14.00 & \\
\hline & Clareon & 10 & 6.30 & 1.89 & 0.60 & 4.95 & 7.65 & 4.00 & 10.00 & \\
\hline & Total & 30 & 6.90 & 2.20 & 0.40 & 6.08 & 7.72 & 3.00 & 14.00 & \\
\hline \multirow{4}{*}{$\begin{array}{l}\text { Opening time } \\
\text { of IOL optics }\end{array}$} & Sensar One & 10 & 25.00 & 6.82 & 2.16 & 20.12 & 29.88 & 12.00 & 30.00 & \multirow{4}{*}{$<0.001$} \\
\hline & Hoya & 10 & 31.40 & 16.33 & 5.16 & 19.72 & 43.08 & 10.00 & 63.00 & \\
\hline & Clareon & 10 & 11.70 & 2.16 & 0.68 & 10.15 & 13.25 & 10.00 & 15.00 & \\
\hline & Total & 30 & 22.70 & 12.97 & 2.37 & 17.86 & 27.54 & 10.00 & 63.00 & \\
\hline \multirow{4}{*}{ Total time } & Sensar One & 10 & 31.30 & 7.15 & 2.26 & 26.19 & 36.41 & 18.00 & 38.00 & \multirow{4}{*}{$<0.001$} \\
\hline & Hoya & 10 & 39.50 & 17.41 & 5.50 & 27.05 & 51.95 & 20.00 & 77.00 & \\
\hline & Clareon & 5 & 19.60 & 2.07 & 0.93 & 17.03 & 22.17 & 18.00 & 23.00 & \\
\hline & Total & 25 & 32.24 & 13.75 & 2.75 & 26.56 & 37.92 & 18.00 & 77.00 & \\
\hline
\end{tabular}

*Analysis of Variance with Welch's Test.

by the Clareon group were not included in this calculation, they were excluded because they do not fully open, this fact may hide a bias.

The clareon IOL had a faster opening of the haptics and had a shorter total time compared to the other groups.

\section{Discussion}

This is the first study to compare injection time and opening time between intraocular lenses. There are no published studies to compare with, regarding those features. Through the evaluation of the recordings of 30 surgeries, it was possible to record the delivery and opening time of the optics between three types of injectors and intraocular lenses and establish the expected average time between the three groups. As a comparison of the data collected from the implant of each IOL group with the opening time of the optic and the total time 
Table 6. Post Hoc analysis for the variables opening time of the IOL optics and total time regarding two preloaded and one conventional injection systems.

\begin{tabular}{|c|c|c|c|c|c|c|c|}
\hline \multirow{2}{*}{\multicolumn{3}{|c|}{ Dependent variable }} & \multirow{2}{*}{$\begin{array}{c}\text { Mean } \\
\text { difference }\end{array}$} & \multirow{2}{*}{$\begin{array}{l}\text { Standard } \\
\text { Error }\end{array}$} & \multirow{2}{*}{$P^{*}$} & \multicolumn{2}{|c|}{ 95\% Confidence Interval } \\
\hline & & & & & & Inferior limit & Upper limit \\
\hline \multirow{6}{*}{ Opening time of IOL optics } & \multirow{2}{*}{ Sensar One } & Hoya & -6.40 & 4.60 & 0.360 & -17.81 & 5.01 \\
\hline & & Clareon & 13.30 & 4.60 & 0.020 & 1.89 & 24.71 \\
\hline & \multirow{2}{*}{ Hoya } & Sensar One & 6.40 & 4.60 & 0.360 & -5.01 & 17.81 \\
\hline & & Clareon & 19.70 & 4.60 & 0.001 & 8.29 & 31.11 \\
\hline & \multirow{2}{*}{ Clareon } & Sensar One & -13.30 & 4.60 & 0.020 & -24.71 & -1.89 \\
\hline & & Hoya & -19.70 & 4.60 & 0.001 & -31.11 & -8.29 \\
\hline \multirow{6}{*}{ Total time } & \multirow{2}{*}{ Sensar One } & Hoya & -8.20 & 5.40 & 0.301 & -21.76 & 5.36 \\
\hline & & Clareon & 11.70 & 6.61 & 0.203 & -4.90 & 28.30 \\
\hline & \multirow{2}{*}{ Hoya } & Sensar One & 8.20 & 5.40 & 0.301 & -5.36 & 21.76 \\
\hline & & Clareon & 19.90 & 6.61 & 0.017 & 3.30 & 36.50 \\
\hline & \multirow{2}{*}{ Clareon } & Sensar One & -11.70 & 6.61 & 0.203 & -28.30 & 4.90 \\
\hline & & Hoya & -19.90 & 6.61 & 0.017 & -36.50 & -3.30 \\
\hline
\end{tabular}

*Tukey's Post Hoc test.

was performed, a statistical correlation between the three groups with the surgical time of IOL implantation was established. Therefore, it is possible to predict changes in surgical time and to seek a strategy to optimize that time in order to maximize the number of surgeries to be performed by the same surgeon.

The study demonstrated that there are no differences between the injectors alone, but there is a statistical difference between the lenses in terms of the opening time and total time. However, there was no difference regarding complications and collateral damage depending on the set chosen for the implant. There may be a bias because all procedures are performed by an experienced surgeon. The group with the best performance time was also the only one that had an unwanted setback, the presence of a haptic stuck.

It is worth remembering that when choosing a monofocal IOL, there are other variables that are taken into account, such as quality and value of the material, and ease of availability for the surgeon to start the procedure [4] [5].

The present study has the limitation of an inferior level of confidence when compared to a prospective study, it cannot determine causation, only association, and it does not aim to rule out a group of injectors and IOLs as a preference for surgeons, but to build a better understanding about their behavior during the intraoperative period.

\section{Conflicts of Interest}

The authors declare no conflicts of interest regarding the publication of this paper. 


\section{References}

[1] Organización Mundial de la Salud (1997) Catarata. In: OMS. Estratégias para la prevención de la ceguera em los programas nacionales. 2nd Edition, OMS, Genebra, 71-77.

[2] Obuchowska, I. and Mariak, Z. (2005) Sir Harold Ridley-The Creator of Modern Cataract Surgery. Klinika Oczna, 107, 382-384.

[3] CBO (2003) Catarata: Diagnóstico e tratamento. Projeto Diretrizes. Associação Médica Brasileira e Conselho Federal de Medicina.

[4] Nanavaty, A.M. and Kubrak-Kiska, M. (2017) Evaluation of Preloaded Intraocular Lens Injection Systems: Ex Vivo Study. Journal of Cataract \& Refractive Surgery, 43, 558-563. https://doi.org/10.1016/j.jcrs.2017.02.019

[5] Mencucci, R., Favuzza, E., Salvatici, M.C., Spadea, L. and Allen, D. (2018) Corneal Incision Architecture after IOL Implantation with Three Different Injectors: An Environmental Scanning Electron Microscopy Study. Springer Science + Business Media B.V. https://doi.org/10.1007/s10792-018-0825-2

[6] Arboleda, A., Arrieta, E., Aguilar, M.C., Sotolongo, K., Nankivil, D. and Parel, J.-M.A. (2018) Variations in Intraocular Lens Injector Dimensions and Corneal Incision Architecture after Cataract Surgery. Journal of Cataract \& Refractive Surgery, 45, 1361. https://doi.org/10.1016/j.jcrs.2019.06.018

[7] Mastropasqua, L., Toto, L., D’ugo, E., Lanzarini, M., Mattei, P.A., Falconio, G., Doronzo, E., Diomede, F. and Trubiani, O. (2019) In Vivo and in Vitro Results of an Automated Preloaded Delivery System for IOL Implantation in Cataract Surgery. Springer Nature B.V. https://doi.org/10.1007/s10792-019-01154-0 